\title{
Pengembangan Aplikasi Inventori Gaya Belajar (IGB) Berbasis Andrioid Bagi Siswa SMA
}

\author{
Irmawati \\ Bimbingan dan Konseling/Universitas Negeri Makassar. \\ Email: irmawatihnD25国gmail.com
}

\section{ABSTRACT}

This study examines the Android-based Learning Style Inventory (IGB) Application for High School Students in Bantaeng Regency. The main problem in this research is that students do not know the learning styles they have and in the school counseling teachers do not have special counseling hours in class. The development research model is the development model Borg and Gall modified by researchers. Research subjects are divided into expert subjects, namely material experts and media experts. The data collection technique was carried out by surveying through interviews, questionnaires and documentation. The data were analyzed by means of content analysis techniques on qualitative data and quantitative analysis techniques. The results of the development research were completed with two test stages, namely the expert test (expert validation) and the small group test, and one revision stage covering; revisions based on expert tests and revisions based on small group tests. revisions were carried out covering several aspects, namely aspects of material content, aspects of media content and applications, usability, feasibility and accuracy and usefulness of the IGB application for students. Based on the expert test material guidance and counseling, the media expert test and learning design and practitioner test get a research scale assessment that is in the very valid category. The learning style inventory (IGB) application in the acceptance test is in a very high category, the product is declared to be used and implemented. Thus, the Android-based Learning Style Inventory (IGB) application developed is said to be appropriate, accepted and can be used for high school students in Bantaeng Regency.

Keywords: Application Inventory Style Learning (IGB) , Android

\section{ABSTRAK}

Penelitian ini menelaah tentang Aplikasi Inventori Gaya Belajar (IGB) berbasis Android bagi Siswa SMA di Kabupaten Bantaeng. Masalah utama dalam penelitian ini adalah siswa tidak mengetahui gaya belajar yang dimiliki serta di sekolah guru BK tidak memiliki jam khusus BK didalam kelas. Model penelitian pengembangan yaitu model pengembangan. Borg and Gall yang dimodifikasi oleh peneliti. Subyek penelitian terbagi atas subyek ahli, yaitu ahli materi dan ahli media. Teknik pengumpulan data dilakukan dengan survey melalui wawancara, angket dan dokumentasi. Teknik analisis data dilakukan dengan teknik analisis isi terhadap data kualitatif dan teknik analisis kuantitatif. Hasil penelitian pengembangan 
diselesaikan dengan dua kali tahap uji, yaitu uji ahli (validasi ahli) dan uji kelompok kecil, serta satu kali tahap revisi meliputi; revisi berdasarkan uji ahli dan revisi berdasarkan uji kelompok kecil.revisi dilakukan meliputi beberapa aspek yaitu aspek isi materi, aspek isi media dan aplikasi, kegunaan, kelayakan dan ketepatan serta kebermanfaatan aplikasi IGB bagi siswa. Berdasarkan uji ahli materi bimbingan dan konseling uji ahli media dan desain Pembelajaran serta uji Praktisi mendapatkan penilaian skala penelitian yang berada dalam kategori sangat valid. Aplikasi inventori gaya belajar (IGB )pada uji keberterimaan berada pada kategori sangat tinggi produk dinyatakan dapat digunakan dan dilaksanakan. Dengan demikian, Aplikasi Inventori Gaya Belajar (IGB) berbasis Android yang dikembangkan dikatakan layak, diterima dan dapat digunakan bagi Siswa SMA di Kabupaten Bantaeng.

Kata Kunci: Aplikasi Inventori Gaya Belajar (IGB), Android

\section{PENDAHULUAN}

Berdasarkan Peraturan Menteri Pendidikan dan Kebudayaan Republik Indanesia Nomor III Tahun 2014 tentang Bimbingan dan Konseling di Sekalah Dasar dan Sekolah Menengah dijelaskan bahwa Layanan Bimbingan dan Konseling bagi Kanseli pada satuan pendidikan memiliki fungsi: (a) pemahaman diri dan lingkungan; (b) fasilitasi pertumbuhan dan perkembangan; (с) penyesuaian diri dengan diri sendiri dan lingkungan; (d) penyaluran pilihan pendidikan, pekerjaan, dan karir; (e) pencegahan timbulnya masalah; (f) perbaikan dan penyembuhan; (g) pemeliharaan kandisi pribadi dan situasi yang kondusif untuk perkembangan diri Konseli; (h) pengembangan potensi optimal; (i) advokasi diri terhadap perlakuan diskriminatif; dan (j) membangun adaptasi pendidik dan tenaga kependidikan terhadap pragram dan aktivitas pendidikan sesuai dengan latar belakang pendidikan, bakat, minat, kemampuan, kecepatan belajar, dan kebutuhan Konseli. Layanan Bimbingan dan Konseling memiliki tujuan membantu Konseli mencapai perkembangan optimal dan kemandirian secara utuh dalam aspek pribadi, belajar, sosial, dan karir. Seorang kanselor yang professional dituntut memahami berbagai karakteristik dari belajar atau proses pembelajaran.Tanggungjawab knnselor/Guru BK sebagai bagian dari sistem pendidikan di lembaga pendidikan formal adalah memberikan pelayanan yang maksimal pada 4 bidang layanan Bimbingan dan Kanseling di Sekalah yaitu bidang Pribadi, bidang Sasial, bidang Belajar dan bidang Karir.

Wayan (2013) menjelaskan bahwa belajar sesuai dengan gaya belajar membuat seseorang dapat dengan mudah menerima pelajaran dan meningkatkan hasil belajarnya. Widayanti (2013) menyatakan bahwa terdapat faktar internal yang selama ini masih kurang diperhatikan dalam usaha memperbaiki kualitas pembelajaran, yaitu gaya belajar (/earning style). Padahal, dalam proses pembelajaran setiap siswa memiliki karakteristik gaya belajar yang berbeda-beda dalam menerima infarmasi. Nihayah (20IC) mengemukakan bahwa mengenali gaya belajar yang tepat merupakan aspek yang tidak boleh di lupakan. terdapat banyak manfaat dan keuntungan yang dapat diperoleh dengan memahami gaya belajar diri sendiri. Beberapa manfaat yang dapat diperoleh di antaranya yaitu memaksimalkan potensi akademik, memahami cara belajar berbaik mengatasi keterbatasan belajar meningkatkan rasa percaya diri mengetahui cara terbaik menggunakan keunggulan otak, mendapatkan informasi kekuatan serta kelemahan diri.

Sampai saat ini, peneliti sudah menemukan aplikasi yang membahas tentang gaya belajar di Play Stare. Namun, aplikasi yang ada belum ada yang mengembangkan teari dari Dryden and Voss dan juga belum ada yang memiliki informasi-informasi penunjang dari jenis inventori gaya belajarnya. Hal ini mendorong peneliti untuk membuat aplikasi Inventori Gaya Belajar berbasis android yang memiliki informasi-informasi penunjang ntuk gaya 
Berdasarkan observasi yang dilakukan peneliti pada empat sekolah SMA Negeri di Kabupaten Bantaeng yaitu SMA Negeri I Bantaeng, SMA Negeri 2 Bantaeng, SMA Negeri 3 Bantaeng dan SMA Negeri 4 Bantaeng pada tanggal 2023 Januari 2020 dengan jumlah responden sebanyak 5 pada setiap sekolah yang diambil secara acak memperoleh kesimpulan bahwa mayoritas siswa-siswi yang ada di 4 Sekalah tersebut menyadari pentingnya mengetahui gaya belajar yang mereka miliki, tetapi di antara 20 responden yang dipilih, tidak ada diantara mereka yang mengetahui gaya belajar yang dimiliki. Berdasarkan hasil wawancara dengan ke 20 respanden didapatkan hasil juga bahwa mereka semua memiliki Andraid, juga mayoritas siswa di ke 4 sekolah yang dilakukan abservasi tersebut memiliki Android. Dalam proses observasi juga didapatkan hasil siswa- siswi di SMA Negeri I Bantaeng, SMA Negeri 2 Bantaeng, SMA Negeri 3 Bantaeng dan SMA Negeri 4 Bantaeng belum dapat menentukaan cara belajar yang terbaik bagi mereka sehingga dengan adanya Aplikasi Inventori gaya belajar ini, para siswa berharap dapat mengetahui gaya belajar mereka sehingga mereka dapat menentukan cara belajar terbaik bagi mereka dan diharapkan juga dapat mengaptimalkan hasil belajarnya.

Berdasarkan wawancara juga yang dilakukan dengan 4 guru BK SMA di Kabupaten Bantaeng, yaitu di SMA Negeri I Bantaeng, SMA Negeri 2 Bantaeng, SMA Negeri 3 Bantaeng dan SMA Negeri 4 Bantaeng pada tanggal 20-23 Januari 2020, didapatkan infarmasi bahwa untuk layanan yang dibberikan kepada siswa masih berbasis kepada masalah, salah satu faktor penyebabnya adalah tidak adanya jam Khusus BK di untuk masuk di kelas sehingga kurang wadah bagi mereka memberikan layanan klasikal terkhusus pada pengembangan 4 bidang yaitu bidang belajar, sasial, belajar dan karir. Hal inilah yang mengakibatkan kurangnya layanan yang diberikan kepada siswa, terkhususnya dalam bidang belajar serta tidak adanya instrument atau media pendukung layanan bidang belajar terkhusus tes gaya belajar juga tidak ada. Dleh karenanya guru BK sangat mendukung adanya Inventori Gaya Belajar sebagai media yang bisa digunakan dalam layanan belajar.

Pandemi CDVID IS menjadi salahsatu penyebab semua proses belajar mengajar yang biasanya dilaksanakan disekolah sekarang dilaksanakan secara daring. Pandemi CDVID IS adalah krisis kesehatan yang pertama dan terutama di dunia. Banyak Negara memutuskan untuk menutup sekolah, perguruan tinggi dan universitas, termasuk Negara Indonesia. Kebijakan yang di ambil leh banyak Negara termasuk Indonesia dengan meliburkan seluruh aktivitas pendidikan, pembuat pemerintah dan lembaga terkait harus menghadirkan alternatif proses pendidikan bagi siswa. Saat ini di Indonesia, beberapa kampus dan sekolah mulai menerapkan kebijakan kegiatan belajar mengajar dari jarak jauh atau belajar secara daring. Layanan bimbingan dan konseling di sekolah juga semakin sulit untuk diberikan secara optimal kepada siswa dengan adanya pandemi CDVID 19 ini. Berdasarkan dari berbagai informasi diataslah yang semakin menguatkan peneliti untuk melakukan penelitian pengembangan berupa Inventari Gaya Belajar yang diharapkan dapat membantu siswa dalam mengidentifikasi gaya belajar yang dimilikinya.

Berdasarkan latar belakang di atas, adapun rumusan masalahnya yaitu:

1) Bagaimana gambaran kebutuhan Aplikasi Inventori Gaya Belajar (IGB) berbasis Andraid bagi Siswa SMA di Kabupaten Bantaeng?

2) Bagaimana protatipe Aplikasi Inventori Gaya Belajar (IGB) berbasis Andraid bagi Siswa SMA di Kabupaten Bantaeng?

3) Bagaimana tingkat validitas dan kepraktisan aplikasi Inventari Gaya Belajar (IGB) berbasis Andraid bagi Siswa SMA di Kabupaten Bantaeng? 


\section{METODE}

Penelitian dilakukan dengan menggunakan pendekatan penelitian Pengembangan (Research and Deve/apment). Sugiyono (2019) yang dimaksud dengan model penelitian pengembangan dalam bahasa inggrisnya Research and Develapmentadalah metade penelitian yang digunakan untuk menghasilkan suatu produk serta menguji keefektifan produk tersebut. Penelitian pengembangan muncul sebagai strategi yang bertujuan untuk meningkatkan kualitas pendidikan, mengembangkan dan memvalidasi hasil-hasil pendidikan. Menurut Barg and Gall (Sugiyono, 2019) mengemukakan bahwa penelitian pengembangan adalah process used to develop and validate educational product

Produk yang dihasilkan dalam penelitian pengembangan ini yaitu aplikasi inventori Gaya Belajar yang dikembangkan dari teori Dryden dan Voss. Didalam aplikasi ini terdapat saal sebanyak 15 buah yang merupakan saal pilihan. Setelah siswa mengerjakan saal tersebut maka akan muncul hasil inventori gaya belajar serta penjelasan dari gaya belajar tersebut yang berisi hal-hal positif, hal-hal sulit dan kiat- kiat jitu dalam belajar berdasarkan jenis gaya belajarnya. Penelitian pengembangan yang dilakukan oleh peneliti yaitu aplikasi inventori Gaya Belajar yang dikembangkan dari teri Dryden dan Voss. Penelitian pengembangan menggunakan panduan ilmiah, setiap tahap pengembangan dilakukan dengan benar agar bisa menghasilkan produk yang baik dan dapat dimanfaatkan oleh pengguna.

Agar media pengembangan ini mengacu pada langkah-langkah pengembangan diatas maka peneliti memodifikasi langkah-langkah pengembangan yang akan dilaksanakan sebagai berikut.
1. Research and Information collecting
2. Planning
3. Develap Preliminary farm a Praduct
4. Main Praduct Revision
5. Main Field Testing
6. Final Praduct Revision

\section{HASIL DAN PEMBAHASAN}

\section{Hasil}

Analisis kebutuhan didasarkan pada asumsi-asumsi dan hasil studi pendahuluan yang dilakukan oleh peneliti melalui kegiatan wawancara (interview) dengan guru BK dan beberapa arang siswa di SMA Negeri 1 Bantaeng, SMA Negeri 2 Bantaeng, SMA Negeri 3 Bantaeng dan SMA Negeri 4 Bantaeng.

Adapun hasil wawancara kepada masing-masing I arang guru BK di SMA Negeri I Bantaeng, SMA Negeri 2 Bantaeng, SMA Negeri 3 Bantaeng dan SMA Negeri 4 Bantaeng, didapatkan informasi bahwa tidak adanya jam khusus Bimbingan dan Konseling melakukan tatap muka di kelas mengakitbatkan layanan Bimbingan dan konseling di sekolah masih berbasis kepada masalah. Guru- guru BK yang ada di SMA Negeri I Bantaeng, SMA Negeri 2 Bantaeng, SMA Negeri 3 Bantaeng dan SMA Negeri 4 Bantaeng pada saat pemberian layanan hanya memberikan infarmasi secara umum. untuk bidang belajar sendiri, guru-guru BK di SMA Negeri I Bantaeng, SMA Negeri 2 Bantaeng, SMA Negeri 3 Bantaeng dan SMA Negeri 4 Bantaeng belum pernah memberikan instrumen atau angket untuk menentukan apa gaya belajar yang cocok bagi siswa karena tidak adanya waktu khusus BK dan tldak adanya juga media pendukung yang dapat membantu para guru BK di sekolah menggali informasi analisis kebutuhan siswa di sekalah.

Rancangan produk yang dibuat berupa aplikasi inventari gaya belajar (IGB) yang dimaksud merupakan hal- 
hal yang dipersiapkan dalam membuat aplikasi inventori gaya belajar (IGB) berbasis andraid bagi siswa SMA. Protatipe (rancang bangun) aplikasi yang dibuat terdiri atas beberapa bagian yaitu halaman depan, tampilan tujuan, tampilan manfaat, tampilan instruksi, tampilan inventori dan tampilan hasil inventori.

Berdasarkan hasil validasi dengan ahli materi Dosen Psiknlogi Pendidikan dan Bimbingan didapatkan hasil bahwa materi dalam aplikasi inventori gaya belajar (ISB) ini layak untuk digunakan dalam penelitian dan layak untuk uji coba lapangan. Berdasarkan hasil validasi dengan Ahli media dan desain pembelajaran didapatkan hasil bahwa rancangan pengembangan aplikasi inventori gaya belajar layak untuk uji coba lapangan dengan revisi kecil.

Adapun hasil uji caba keelompok kecil ysng diberikan kepada 20 siswa SMA di Bantaeng antara lain sebagai berikut

\begin{tabular}{|c|c|c|c|}
\hline \multirow{2}{*}{ Pertanyaan } & \multicolumn{2}{|c|}{ Jawaban Siswa } & \multirow{2}{*}{$\%$} \\
\hline & Ya & Tidak & \\
\hline $\begin{array}{l}\text { Apakah tampilan Aplikasi IGB sudah } \\
\text { Menarik? }\end{array}$ & 20 siswa & - & $100 \%$ \\
\hline $\begin{array}{l}\text { Apakah aplikasi IGB menggunakan bahasa } \\
\text { yang mudah dipahami? }\end{array}$ & 19 siswa & 1 siswa & $95 \%$ \\
\hline $\begin{array}{l}\text { Apakah aplikasi IGB mudah untuk } \\
\text { dijalankan? }\end{array}$ & 19 siswa & 1 siswa & $95 \%$ \\
\hline $\begin{array}{l}\text { Apakah soal pernyataan dalam aplikasi IGB } \\
\text { mudah dimengerti? }\end{array}$ & 19 siswa & 1 siswa & $95 \%$ \\
\hline $\begin{array}{l}\text { Apakah hasil inventori dari aplikasi ini } \\
\text { bermanfaat bagi anda? }\end{array}$ & 20 siswa & - & $100 \%$ \\
\hline $\begin{array}{l}\text { Apakah aplikasi ini memberikan informasi } \\
\text { cara belajar terbaik bagi anda? }\end{array}$ & 19 siswa & 1 siswa & $95 \%$ \\
\hline
\end{tabular}

\section{Pembahasan}

Berdasarkan hasil informasi dan need assesmentyang diperoleh dari siswa dan guru BK, hasil kajian teoritik dan empirik sangatlah diperlukan hadirnya pemberian layanan bimbingan dan konseling yang menarik dan inovatif guna membau siswa dalam peningkatan hasil belajarnya. Sejalan dengan analisis kebutuhan telah dilakukan melalui pengumpulan informasi, sebelum melakukan pengembangan aplikasi inventori gaya belajar (IGB) dilakukan sudi literatur mengenai aplikasi inventori gaya belajar (IGB). Studi literatur dan need assesment untuk mengetahui kebutuhan guru BK di sekolah mengenai area implementasi model pengembangan.

Pengembangan aplikasi inventori gaya belajar (IGB) merujuk pada need assesment dan asumsi bahwa dalam perkembangan penyelenggaraan konseling di sekolah masih berbasis kepada masalah. Dryden \& Voss (Wahyudi c Azizah, 20IG) menjelaskan bahwa dalam proses pembelajaran dibutuhkan perubahan secara cepat dan mendalam pada cara belajar perlu dilakukan agar kemungkinan- kemungkinan baru yang lebih ideal yang diberikan oleh teknologi infarmasi dapat berguna bagi proses pembelajaran yang lebih maju dengan berusaha memanfaatkan kemajuan IPTEK yang berkembang kian pesat guna meningkatkan kualitas pendidikan serta memunculkan inavasi pembelajaran yang lebih tepat bagi tercapainya tujuan pendidikan. Dengan demikian, pengembangan aplikasi 
inventari gaya belajar (IGB) dianggap penting, sebagai salah satu inovasi dalam bimbingan dan konseling untuk mengidentifikasi gaya belajar yang dimiliki oleh siswa. Menurut wiedarti (2018), dengan mengetahui gaya belajar siswa, mereka diharapkan dapat menyerap informasi secara maksimal bergantung pada pembelajaran berlangsung sesuai gaya belajarnya dan bagi guru, agar ia dapat memfasilitasi pembelajaran di kelasnya sesuai dengan gaya belajar yang disukai siswa.

\section{SIMPULAN DAN SARAN}

Berdasarkan hasil penelitian dan pembahasan di bab sebelumnya, maka dapat disimpulkan bahwa Gambaran kebutuhan siswa tentang aplikasi inventori gaya belajar (IGB) yang diperoleh dari need asessmet dengan menggunakan wawancara dengan guru BK dan siswa SMA di Kabupaten Banrtaeng sangat membutuhkan aplikasi inventori gaya belajar (ISB) untuk mengidentifikasi gaya belajar yang dimiliki serta mengoptimalkan hasil belajarnya. Protatipe aplikasi inventori gaya belajar (IGB) berbasis andraid bagi siswa SMA di Kabupaten bantaeng yang dirancang terdiri atas enam bagian tampilan yaitu halaman awal, tujuan, manfaat, instruksi, tampilan inventori dan tampilan hasil. Tingkat validitas aplikasi Inventori Gaya Belajar (IGB) berada pada kategori tinggi, sementara tingkat kepraktisannya berada pada kategori tinggi. Dengan demikian, Aplikasi Inventori Gaya Belajar (IGB) valid dan praktis untuk digunakan di sekolah sebagai media penunjang layanan Guru BK dengan siswa.

Berdasarkan kesimpulan hasil penelitian diajukan saran Bagi guru agar memanfaatkan Aplikasi Inventori Laya Belajar (IGB) dalam pemberian layanan bidang belaajar kepada siswa khususnya untuk mengidentifkiasi gaya belajar yang dimiliki tiap siswa. Bagi peneliti selanjutnya agar dapat mengembangkan aplikasi Inventori Gaya Belajar pada system operasi mabile lainnya.

\section{DAFTAR RUJUKAN}

Aryani, F. dan Rais, M. 2018. Bimbingan Karir Masa Depan untuk Meraih Sukses ke Perguruan Tinggi. Makassar: Badan Penerbit UNM.

Budiman, A. dkk. 2014. Aplikasi Interaktif Pengenalan Pahlawan Revalusi Indanesia Berbasis Multimedia (Studi Kasus di MI AL- GINA). Jurnal Sisfatek Glabal. Vol 4 №. 2.

Chania. Dkk. 2016. Hubungan Gaya Belajar dengan Hasil Belajar Siswa pada Pembelajaran Biolagi Kelas X SMAN 2 Sungai Tarab Kabupaten Tanah Datar. Jurnal of Saintek Vol 8.

Danial, A. Resky Amaliyah. Pengembangan Modul Bimbingan Karir untuk Meningkatkan Perencanaan Studi Lanjut Siswa di SMA Negeri 2 Sinjai. Skripsi. Universitas Negeri Makassar.

Hasrul. 2009. Pemahaman tentang Gaya Belajar. Jurnal Medtek. Vol INo.2.

Jumiati, Pengembangan Modul Bimbingan Pribadi Sasial Untuk Meningkatkan Kemampuan Resolusi Konflik Siswa SMA Negeri 3 Takalar. Skripsi. Universitas Negeri Makassar.

Kanta, Kulasse. 2015. Prinsip-Prinsip Bimbingan dan Kanseling Belajar. Makassar: Badan Penerbit UNM. 

Namar III Tahun 2014 tentang Bimbingan dan Kanseling pada Sekalah Dasardan Pendidikan Menengah. Jakarta: Kementerian Pendidikan dan Kebudayaan.

Lee, Wei-Meng. 20II. Beginning Andraid Applicatian Develapment. Indiana: Wiley Publishing.

Mashurwati, Yuyun. 2018. Penerapan Inventary Tes Gaya Belajar Remaja dengan Aplikasi Gougle Form, Media Sasial serta Pengembangan Pragram Layanan Bimbingan dan Kanseling Terkait Jurnal Educatio Vol 4 No. I.

Nasution, S. 2DII. Berbagai Pendekatan Dalam Proses Belajar dan Mengajar. Jakarta: Bumi Aksara.

Nazruddin Safaat, 2014. Pemprograman Aplikasi Mabile Smartphone dan tablet PГ Berbasis android (Revisi kedua). Bandung: Informatika.

Nihayah, Fista. Profil Gaya Belajar (Learning Sty/e) dan IPK Mahasiswa Jurusan Biologi FMIPA UNNES. Skripsi. Universitas Negeri Semarang.

Nour, Agustina. 2017. Aplikasi Belajar Mengajar pada Labaratorium Kamputer Teknik Informatika dengan Sidik Jari Berbasis Web Dekstap. Jurnal Sains dan Informatika. Vol 2.

Nursalim, Mochamad. 2013.

Pengembangan Media Bimbingan dan Kanseling.Jakarta:Indeks.

Pariani, Elva.Hubungan antara Gaya Belajar dengan Hasil Belajar Mata Pelajaran Akidah Akhlak Siswa Kelas V di MI Negeri 12 Bandar Lampung Tahun Ajaran 2016/2017. Skripsi. Universitas Islam Negeri Raden Intan Lampung. Santiosa, Lucy Lidiawati. 2010. Mendidik Sesuai Dengan Minat \& Bakat Anak. (Cetakan ke-2). Jakarta: PT Tangga Pustaka.

Sriyanta, H.J. dkk., 2007. Langkah Jitu Menghadapi UN SMP. Yogyakarta: Indanesiatera.

Sugiyono. 20I6. Metade Penelitian Pendidikan Pendekatan Kuantitatif, Kualitatif, dan RॄD. Bandung. Cv. Alfabeta.

Sugiyona, 2019. Metade Penelitian Pendidikan Kuantitatif, Kualitatif, Kambinasi, R \& D dan Penelitian Pendidikan. Bandung. CV Alfabeta.

Suhartano, S. 2009. Filsafat Pendidikan. Makassar: Badan Penerbit UNM.

Tanta. 2010. Pengaruh Gaya Belajar Terhadap Hasil Belajar Pada Mata Kuliah Biologi Umum Program Studi Pendidikan Biologi Universitas Cenderawasih. Jurnal Kependidikan Dasar Vol I.

Undang-Undang Republik Indanesia Nama2 20 Tahun 20D3 tentang system Pendidikan Nasional. 20D6. Legal Agency.

Ulfa, Mareta. Hubungan Gaya Belajar terhadap prestasi Belajar Ilmu Pengetahuan Sasial Siswa Kelas V SD Negeri ID Metro Timur. Skripsi. Universitas Lampung. 
Wahyudi, Dedi \& Azizah, Habibatul. 2016. Strategi Pembelajaran Menyenangkan dengan Kansep Learning Revalution. Attarbiyah Vol 26

Wayan, A, dkk. 2013. Implementasi Strategi Pembelajaran Inkuiri Terhadap Kemampuan Berpikir Kritis dan Pemahaman Kansep IPA Siswa SMP. e- Jaurnal Program Pascasarjana Universitas Pendidikan Ganesha. Vol 3.

Widayanti, F. D. 20ID. Pengaruh Penge/ompakan Siswa Berdasarkan Gaya Belajar dan Multiple Intelligences ERUDID, Vol. 2.

Wiedarwati, P. 2018. Seri Manual GLS Pentingnya Memahami Gaya Belajar. Jakarta: Direktorat Jenderal Pendidikan Dasar dan Menengah Kementerian Pendidikan dan Kebudayaan.

Wei Meng Lee 20Il. -Beginning Andraid ${ }^{T M}$ Application Develapment" Canada: Wiley Publishing, 